\title{
The effect of noise on motor task functioning among young motorcyclist: A controlled experiment
}

\author{
Anila Ali ${ }^{a^{*}}$, Roslinah Mohamad Hussain ${ }^{\text {a }}$, Ali Asghar a, Syed Zameer Ul Hassan ${ }^{\text {b }}$, Gohram Khan \\ Malghani ${ }^{\mathrm{c}}$, Samiullah Khan ${ }^{\mathrm{c}}$, Nazri Che Dom ${ }^{\mathrm{a}}$, Muhammad Qasim Khan ${ }^{\mathrm{d}}$ \\ ${ }^{a}$ University Technology Mara, Malaysia \\ b Technical University of Liberec, Czech Republic \\ ${ }^{c}$ University Technology Malaysia \\ ${ }^{\mathrm{d}}$ Sungkyunkwan University (SKKU), Suwon, 16419, Korea
}

*Corresponding author email: anila928@yahoo.com

\begin{abstract}
Motorcycle is a complex machine, and its riding requires mental alertness along with mind and body coordination. On the road, motorcyclists are subjected to excessive level of noise ( $>90 \mathrm{dBA})$. High noise exposure can impair the motor task functioning. The assessment of motor task (dexterity) of motorcyclists under noise exposure has not been examined formerly as well as their psychological health profiling. Therefore, this study is aimed to investigate the effects of noise-induced motor task functioning among young motorcyclists $(19-24$ yrs.). The controlled laboratory experiment was conducted on undergraduate university motorcyclists $(n=60 ; 30$ males, 30 females). Two groups were formed experimental (Exp-G; $n=30)$ and a controlled (Con-G; $n=30)$. The Exp-G operated motor activity test under 85-90 dBA motorcycle noise exposure, while Con-G exposed to controlled noise (65 dBA) levels. The sound level was examined concurrently by calibrated (114 dBA) Sound Level Meter. Purdue Pegboard battery test was used to measure motor task functioning consisting four subtests (Dominant Hand; Non-Dominant Hand; Both Hands; Assembly). The Independent sample $t$-test was used across all subtests to examine the comparison effect of motor task function (dexterity) between Exp-G and Con-G, and amongst genders. Result showed that the Con-G had significantly good quality presentation $(p<0.05)$ in all the subtests of Purdue Pegboard as compared to Exp-G. Gender differences were not found statistically significant $(p>0.05)$. Based on mean values, male participants of the Exp-G performed better under high noise levels than females, while among Con-G, females performed better. The results demonstrated significant effect of motorcycle noise on decreased motor task functioning of the participants (Exp-G). Therefore, it concludes that on-road excessive noise level exposure can hinder the motor task functioning and can contribute to impair the reaction time on excruciating hazardous position.
\end{abstract}

Keywords- Dexterity; Motor activity; Noise; Perdue Pegboard.

Date Received: $30-10-2020$

Date Accepted: 25-05-2021

Date Published: 08-06-2021

\section{INTRODUCTION}

$\mathrm{W}$ ith rapidly growing trend in motorization, motorcycle became the dominant mode of transportation in Asian countries [1]. It is treated both as main and intermediate mode of transport, before switching to the use of cars in the developing countries of Asia. Malaysia is categorized as a middle income or newly industrialized country, where motorcycle is the most convenient mode of transportation [2]. In Malaysia, the traffic type (like most of the Asian countries) is mixed traffic and includes motorcycles. Their presence often leads to interrupted hazardous traffic flow and reportedly resulted in more Road Traffic Injuries (RTI) [3]. According to WHO (2013), RTI is the leading cause of death by injury, placing it in ninth position as a burden of disease and in tenth position as leading cause of all deaths. By 2030, it is expected to be the most important issue as it is predicted to be the fifth leading cause of deaths [4]. Among the increasing number of road casualties, motorcycles will remain the major contributors to road fatalities [5]. Reported motorcycle fatalities are nearly 3, 6 and 50 times higher than car, pedestrian and bus passengers fatalities respectively [6]. Motorcyclists are the most vulnerable road users in the case of traffic crashes [7][8], at approximately 20 times higher risk than car passengers, measured per $\mathrm{km}[9][10]$. The Royal Malaysian Police reported a significant proportion of motorcycle fatal accidents in its national statistics; whereby motorcycle road accidents have been the number one cause of road traffic fatalities for five consecutive years [11].

The reason behind motorcycle injuries is often reported as "Human Error" [10][12]. There are number of causes related to road accidents involving motorcyclists; reasons may include poor maintenance of vehicle, vehicle deficit, poor road maintenance or poor road design. It is articulated in several reports that human error is $90 \%$ of the cause of all road traffic injuries [9]. Human errors are usually referred under an umbrella term as fault of victim with numerous factors such as lack of sleep, fatigue, excessive speed, inattentiveness, perceptual errors, lack of concentration [12]. All these human 
errors and factors are associated with psychological malfunctioning of the drivers [13][12][14][15], as motorcycling requires excellent motor skills and physical coordination. Driver's impairment is considered as a key factor in road traffic accidents worldwide [16]. However, root cause behind the riders psychological malfunctioning has never been investigated.

With an increasing trend in the use of motorcycles, it not only contributes to road accidents but also to noise pollution [17]. Motorcycle is regarded as an economical vehicle, which saves travelling time and fuel and provides ease for parking [18], however, it is noisiest form of transportation. Motorcycle performance has improved with advancement in technology for quieter machines but the drivers are exposed to turbulent air flow around the helmet, which creates excessive noise termed as wind noise [19]. Daily exposures of noise level that motorcycle riders may typically experience exceeds $90 \mathrm{dBA}$ [20].

Literature on the chronic effects of traffic, aircraft and rail noise on humans and animals documents the detrimental impacts of high noise exposure on health [21]. Therefore, the effects of high noise exposure on drivers requires attention in the scientific field. Daily exposure to excessive noise activates a physiological stress response in body, which leads to poor mind body function coordination. Noise generated from acceleration in motorcycling is higher than any other type of traffic vehicle [22]. Hence, motorcycle riders are expected to be the most vulnerable amongst noise exposed population, while the most vulnerable exposed group in motorcycle road accidents are young riders aged between 15 - 29 [4].

Motorcycle is a complex machine and riding requires mental alertness along with mind and body coordination [23]. Mental alertness and physio-psycho coordination can be affected by noise exposure. On the road, the long-term motorcycle riders are exposed to high intensity noise ( $>90 \mathrm{dBA}$ ) on a daily basis [24];[25];[26]. They are exposed to traffic noise, in addition, wind flow around their helmet generate noise above $90 \mathrm{dBA}$ [27]. Chronic noise exposures also tend to deteriorate, especially, selective attention, working memory, declarative memory and learning. Noise stimulates cortisol in the body at each on set, which remains in the body and can hinder the riders cognitive functioning [28] such as attentiveness, perceptual abilities, spatial abilities, motor coordination, and memory which can lead to fatal or injurious accident [29].

For the performance of a task, dexterity is required which is a skill and ease in use of hands. It is defined as "the ability to adequately solve any motor task, precisely, quickly, rationally and deftly", where change in the environment is an important factor. Dexterity does not imply only to the tasks involving hands, indeed at the behavioural level, loss of dexterity involves the loss of ability to coordinate muscle activity as per environmental demands. At the neurophysiological level, it means impaired processing of multiple corticospinal channels, which are responsible for rapid conduct of sensorimotor information between the cerebral cortex and the spinal. The Purdue Pegboard Test is one of the most utilized assessments for hand function purpose as developed by Dr Joseph Tiffin, an Industrial Psychologist at Purdue University (Tiffin., 1948). It determines the quality and speed of hand performance to accomplish a task. It also assesses proficiency of grasping pattern and the precision grip.

However, the aspect of young motorcyclist's noise-induced impaired motor activity and its possible detrimental effects on riders' immediate cognitive and physiological functioning has not been studied. This study will deliver a vast audience globally, primarily due to increasing trends in motorcycle ownership and usage. Secondly, due to increasing number of road accidents comprising of young motorcycle drivers, it would capture the attention of the policy makers to address the health-related consequences that are associated with motorcycling at a young age. Noise induced impaired motor activity assessment of motorcyclists may highlight the importance of acknowledging noise related motor impairment, which could be one of the contributing factors towards road mortality and morbidity. The purpose of this study was to understand the impact of high noise exposure on the ability to coordinate muscle activity in the performance of a motor task among young motorcyclists $(19-24$ yrs.). Motorcycle rider's psychological health profiling is scarce, while motor activity assessment under motorcycle noise exposure has not been investigated previously. Therefore, this study is aimed to determine the effects of noise-induced motor functioning and gender differences.

\section{MATERIALS AND METHODS}

\section{A. Participants}

This experimental study was conducted on undergraduate students at Universiti Teknologi MARA Selangor, Puncak Alam campus, Malaysia. A Simple random technique was adopted for sampling across eight faculties, representing from all over Malaysia [30]. Participants aged between $19-24$ years, from semester 2 till 8 . Participants had been occupying and driving motorcycle as primary means of transportation as daily commute for a minimum of one year. Participants inclusion criteria for the study included (a) aged from 19 to 24 yrs. [31]; (b) non-smokers; (c) absenteeism of any chronic ailments and CGPA (Cumulative Grade Point Average) above 2.5.

A set of structured questionnaires, which consisted of study information sheet and respondent's demographic survey were distributed among 197 motorcyclists. Total participants recruited in the experimental phase were 60 (30 male and 30 female), composed on exclusion and inclusion criterion. Participation of the participants was permitted on transcribed consent-form before the commencement of the experiment. Experimental design, sampling and procedure were approved by Faculty's (Health Sciences) Internal Ethical Committee (600-FSK (PT.5/2)), Universiti Teknologi Mara, Malaysia.

\section{B. Demographic Information}

Demographic information of the participants was acquired using a closed-end questionnaire. It comprised of information related to age, gender, motorcycling driving experience (as a primary mode of transportation), faculty, the enrolled semester, CGPA of proceeding semester, tobacco smoking habit, past history of any neurological disorders and any chronic ailment (asthma, diabetes mellites, arthritis, hypertension). 


\section{Sound Level Meter (SLM)}

SoundPro SE and DL sound level meter (SLM) of class/type 1 (serial no BEI040002) from Quest Technologies Oconomowoc, WI, USA, was utilized for measuring the laboratory sound level during test administration. Type 1 sound level was operated for measuring the ambient noise as induced artificially (motorcycle noise). SLM was calibrated (114 dBA) before and after each test session, while it was being operated throughout the test administration of each subsequent testing session.

\section{Purdue Pegboard}

Purdue Pegboard battery test is made up of Acrylic board used to assess the fine motor control by using the standardized testing procedure (Desrosiers et al., 1995). The length and breadth of the board is 23 and 11.5 inches, respectively. There are 2 centre rows, each having 25 holes and 4 reservoirs across the top for pins $(50,85 \mathrm{gms})$, collars $(25,10 \mathrm{gms}), \&$ washers (40, gms). It consists of four subtests. The first subtest is for Dominant Hand activity (DH; unimanual), which requires the participant to insert pins into the holes in the pegboard with their preferred hand, one at a time within the period of 30 seconds. Scoring is based on each properly inserted pin, which is equal to 1 point. The second subtest is related to NonDominant Hand activity (NDH, unimanual), performed from non-preferred hand, and follows the same procedure timing and scoring as of DH. The third subtest requires Both Hand activity (BH; bimanual) to perform the same task with both hands simultaneously, within the period of 30 seconds and each pair of pins inserted is equal to point 1 . The fourth subtest is Assembly activity (sequencing) which consists of assembling pins, collars, \& washers in a sequence. There were three trial per subtest and participants completed one practice trial per subtest. The order of battery subtests requires counterbalance across the participants. The completion of Purdue pegboard battery test in one testing requires approximately $25 \mathrm{~min}$. Higher the scores better the fine motor control. Purdue pegboard has good test re-test reliability $(0.69-0.91$; Desrosiers et al., 1995).

\section{E. Laboratory setting}

Figure 1 illustrates the detailed laboratory setting for conducting the controlled experimental study for assessing the noise-induced fine motor function. Laboratory setup consisted of a front table, which was set up to enable face to face interaction between examiner and participant. The person to be tested was seated comfortably at normal height table (at approximately $30 "$ "). It was placed on the opposite end of the air-conditioner to minimize the direct influence of low frequency noise on the participants auditory and non-auditory system. Laboratory was pleasantly ventilated and was adequately lightened. Speakers were placed on right and left side of the participants on the front table. Speakers (Long lorn model SP -MN 019/U, with output RMS 3Wx 2, signal-to-noise $(\mathrm{S} / \mathrm{N})$ ratio $80 \mathrm{dBA})$ was attached with personal computer to play the audio clip of motorcycle noise.

\section{$\boldsymbol{F}$. Experimentation Process}

The experimental study design consisted of the performance on Purdue Pegboard battery test under controlled laboratory setting (Figure 2). Two groups of participants were constituted: Control Group (Con-G; $n=30$ ) and Experimental Group (Exp$\mathrm{G} ; n=30$ ). Upon participant arrival, 10 minutes of relaxation period provided to each participant and followed with the performance of fine motor battery test. Con-G performed the test in conjunction with normal laboratory noise levels $(\leq 65$ dBA). However, Exp-G performed along with background motorcycle noise $(85-90 \mathrm{dBA})$.

Operational definitions of the variables used in the experiment consisted of two independent variables: noise (motorcycle and normal background sound) and Perdue Pegboard battery tests. For the Exp-G noise level was artificially induced in the background, while the $\mathrm{CoG}$ had controlled background (ambient) noise. Dependent variable was the performance on the fine motor battery test. Controlled variables were fine motor battery test administration, laboratory setting, lightening, sound and examiner. Confounding factors were controlled by using standardized instructional procedures for both the groups.



Fig. 1. Laboratory setup for Purdue Pegboard Administration

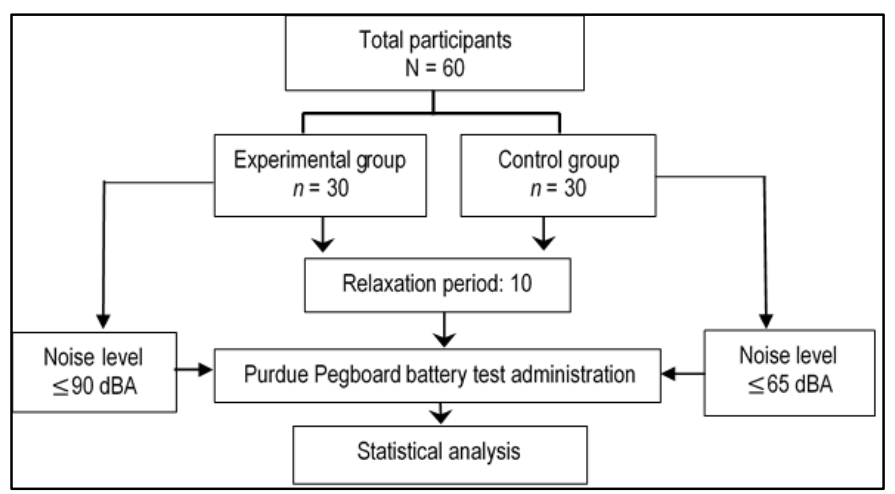

Fig. 2. Experimentation flow-chart of Purdue Pegboard Battery Test

\section{G. Statistical Analysis}

First category of data analysis involved data tabulation and logging of Participants information and Purdue Pegboard battery test scoring data on excel worksheet for database and computation for statistical analysis through Statistical Package for Social Sciences, IBM SPSS (Version 22 Inc., Chicago, IL). Descriptive analysis of the variables such as: age, gender, semester, and driving experience were determined using 
descriptive analyses. The internal consistency of Purdue Pegboard battery test (4 items) for Exp-G and Con-G were computed through Cronbach Alpha $(\alpha)$. The homogeneity of variances and normality were tested through Shapiro-Wilk test, $p>0.05$.

Second category of analysis was conducted to evaluate the difference in Purdue Pegboard battery test performance between the Exp-G and Con-G groups, as well as gender differences among the groups. The statistical technique adopted was Independent sample $t$-test for all subtests of the battery test. Data was deemed to be significant at $p$-value $<0.05$ for subsequent analysis. Bar charts are also plotted to display the comparisons within groups as generated on Microsoft Excel Spreadsheet.

\section{RESULTS AND DISCUSSION}

\section{A. Descriptive Profile of Participants}

Participants $(n=60)$ demographic profile (Table 1$)$ of the laboratory experiment for exploring the effects of noiseinduced fine-motor function was equally participated by males and females. Participants mean age ranged from 19 to 24 years $(M=22, S D=.9)$, enrolled in semester between 2 to $8(M=5$; $S D=1.5)$ while the driving experience ranged between 1 to 9 years $(M=6.2 ; S D=2)$. Participants averaged CGPA of previous semesters ranged between 2.5 to $3.9(M=3.1 ; S D=$ 1).

The participation in control group was comprised of $56 \%$ males $(n=17)$ and $43 \%$ females $(\mathrm{n}=13)$. Participants aged between 20 to 24 years $(M=22 ; S D=.9)$, enrolled in semester between 2 to $7(M=4 ; S D=1)$, while motorcycle driving experience ranged between 1 to 9 years $(\mathrm{M}=6.7 ; S D=1.9)$. The average CGPA of the participants was $3.2(S D=.5)$, ranged from 2.5 to 3.9. Experimental group participants constituted more of female riders $(n=17)$ then males $(n=13)$, aged between 19 to 24 years $(M=22 ; S D=1)$, enrolled from semester 2 to $8(M=4.5 ; S D=1.5)$ with average CGPA of $3.3(S D=.4)$, ranged between 2.5 to 3.5 . Participants motorcycle driving experience ranged between 3 to 9 years $(M=6.7 ; S D=1.9)$.

TABLE I

Demographic profile of participants

\begin{tabular}{|c|c|c|c|c|c|c|}
\hline \multirow{2}{*}{$\begin{array}{l}\text { Variables } \\
\text { Gender (M/F) }\end{array}$} & \multicolumn{2}{|c|}{$\begin{array}{c}\text { Total } \\
N=60\end{array}$} & \multicolumn{2}{|c|}{$\begin{array}{c}\text { Control Group } \\
n=30\end{array}$} & \multicolumn{2}{|c|}{$\begin{array}{l}\text { Experimental group } \\
\qquad n=30\end{array}$} \\
\hline & \multicolumn{2}{|c|}{$30 / 30$} & \multicolumn{2}{|c|}{$17 / 13$} & \multicolumn{2}{|c|}{$13 / 17$} \\
\hline & $M \pm S D$ & range & $M \pm S D$ & range & $M \pm S D$ & range \\
\hline Age, (yrs.) & $22 \pm .9$ & $19-24$ & $22 \pm .9$ & $20-24$ & $22 \pm 1$ & $19-24$ \\
\hline Semester & $5 \pm 1.5$ & $2-8$ & $4 \pm 1$ & $2-7$ & $4.5 \pm 1.5$ & $2-8$ \\
\hline Driving age & $6.2 \pm 2$ & $1-9$ & $5.6 \pm 1.9$ & $1-9$ & $6.7 \pm 1.9$ & $3-9$ \\
\hline CGPA & $3.7 \pm 2$ & $2.5-3.2$ & $4.2 \pm 5.2$ & $2.5-3.2$ & $3.3 \pm .4$ & $2.5-3.9$ \\
\hline
\end{tabular}

\section{B. Descriptive Analysis of the Participants Purdue Pegboard Battery Test}

The internal consistency for Purdue Pegboard Battery test (4 items) was calculated using Cronbach's alpha for both the groups i.e. Exp-G $(n=30)$ and Con-G $(n=30)$. The estimated value of the coefficient of reliability for the Con-G was found statistically higher reliability with $\alpha=.724$, while Exp-G was found with medium value i.e. $\alpha=.512$. The descriptive and statistical analysis of the Purdue Pegboard battery test assessment across all subtests for both the groups (Exp-G and
Con-G) is presented in Table 2, and also providing the knowngroup validity of Purdue Pegboard on Malaysian Adults (1924 yrs.). Figure 3 shows the difference between Purdue Pegboard subtests average scores of Con-G and Exp-G, expressed as percentage. Higher percentage scores of Con-G as compared to Exp-G, displays its better overall performance,

The first subtest of Purdue Pegboard i.e. Dominant Hand battery test performance was found significantly higher in Con$\mathrm{G}(M=15.1, S D=1.4)$ as compared to Exp-G $(M=13.6, S D=$ $1.4), t(4.2)=58, p=0.000$. Figure $2 \mathrm{~A}$ shows the difference in Dominant Hand performance between Exp-G (ranging: $11-$ 15) and Con-G (ranging: 12.6 - 18), which indicates the impact of noise on Exp-G participants' lower performance as compared to better performance of the Con-G participants.

Non-Dominant Hand performance on the second subtest of Purdue Pegboard battery test was also found significantly higher in Con-G $(M=13.8, S D=1.5)$ as compared to Exp-G $(M=13, S D=1.5), t(2.4)=58, p=0.022$. Figure 2 indicates the impact of noise on Exp-G participants (ranging: $11-14$ ) lower performance as compared to better performance of the Con-G participants (ranging: $11.3-17$ ) on the NON-Dominant hand performance on the battery test.

The third subtest of Purdue Pegboard i.e. Both Hands performance of the Con-G participants $(M=12.5, S D=1.3)$ was also found significantly higher as compared to Exp-G participants $(M=11.6, S D=1.3), t(2.5)=58, p=0.017$. Figure 2 shows the difference in Both Hands performance on the battery test between Exp-G and Con-G, which signifies the influence of noise on Exp-G participants lower performance (ranging: $9.3-14$ ) as compared to better performance of the Con-G participants $(10-14.6)$.

The forth subtest of Purdue Pegboard i.e. Assembly of the battery test performance was also found significantly higher in Con-G $(M=33.4, S D=3.1)$ as compared to Exp-G $(M=30.4$, $S D=4.1), t(3.1)=58, p=0.003$. Figure 2 shows the difference in the Assembling of the battery test performance between Exp$\mathrm{G}(22.3$ - 36.6) and Con-G (ranging: 29 - 40), which suggests the negatively influencing impact of noise on Exp-G participants performance as compared to better functioning of the Con-G participants.

Affected hand performance (Purdue Pegboard) across all subtests by the Exp-G participants imply a reduction in performance due to exposure to the high intensity $(\leq 90 \mathrm{dBA})$ motorcycle noise. Overall, both the groups (Exp-G and Con-G) obtained the average scores very close to the maximum possible in each subtests (average score) and showed a significant difference $(p<0.05)$ in the performance of Exp-G participants, which can be attributed to the effect of noise exposure $(\leq 90$ $\mathrm{dBA}$ ). Hence, it can be concluded that Purdue Pegboard is a simple neurophysiological battery test but the difference in performance quantifies the effect of noise exposure $(\leq 90 \mathrm{dBA})$. Other experimental studies, which evaluated the effect of noise (office noise and low frequency noise) on mental performance on different populations, showed significantly impaired performance [32];[33];[34]. Precise comparison with other research is difficult because other study's source and level of noise was vastly different, as well as the nature of neurophysiological battery test used to assess the motor performance.

Disruption in visual attention has an adverse effect on daily 
activity functioning, mainly that require integration of visual details associated with the dynamic environment such as riding a motorcycle [35]. According to Parsons visual performance is affected by high-intensity noise. It can be concluded that with motorcycle noise exposure, motorcyclists visuomotor activity (motor function) can be affected [36] and therefore, can pose a safety risk associated with motorcycling. It has also been reported that prolonged noise exposure degenerates neurophysiological and cognitive function and may possibly increases the risk of accidents [12]. Another review study [37] stated that noise is associated with several indicators of neurocognitive function, mood disorders and neurodegenerative diseases in long-term noise-exposed population.

Time pressure can also affect the judgment of workload by a decline in performance [38]. During this experimental study, time administration of the Purdue Pegboard test was kept constant, which might have put the participants under time pressure. A review study by Liebl \& Jahncke [33] , investigated the effects of noise on cognitive performance and reported that individuals with lower working capacity (cognitive function) are more vulnerable to noise effects. For this reason, all participants CGPA ranged above medium.

\section{TABLE 2}

Descriptive and statistical analysis of the Purdue Pegboard

\begin{tabular}{lcccccc}
\multicolumn{7}{c}{ assessment } \\
\hline Purdue Subtests & Groups & Mean \pm SD & Range & Minimum & Maximum & P-Value \\
\hline Dominant Hand & Experimental & $13.6 \pm 1.4$ & 4 & 11 & 15 & .000 \\
& Control & $15.1 \pm 1.4$ & 5.4 & 12.6 & 18 & \\
\multirow{2}{*}{ Non-Dominant } & Experimental & $13 \pm 1.3$ & 3.6 & 11 & 14 & .022 \\
Hand & Control & $13.8 \pm 1.5$ & 5.7 & 11.3 & 17 & \\
Both Hands & Experimental & $11.6 \pm 1.3$ & 4.7 & 9.3 & 14 & .017 \\
& Control & $12.5 \pm 1.3$ & 4.6 & 10 & 14.6 & \\
Assembly & Experimental & $30.4 \pm 4.1$ & 14.3 & 22.3 & 36.6 & .003 \\
& Control & $33.4 \pm 3.1$ & 11.6 & 29 & 40 & \\
\hline
\end{tabular}

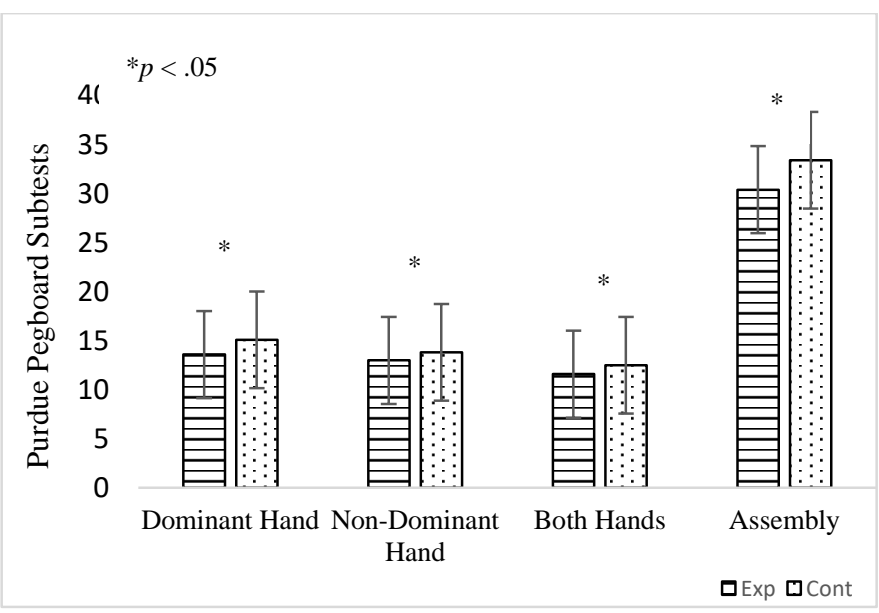

Fig. 3. Purdue Pegboard subtests comparison among Experimental (Exp-G) and Control (Con-G) group

Note: ${ }^{*}$ p-value generated from Independent Sample t-test

\section{Gender Analysis of Purdue Pegboard Battery Test}

Error! Reference source not found. presents the gender differences among Exp-G and Con-G participants. Gender differences among Exp-G participants were not found significant $(p>0.05)$ for any Purdue Pegboard subtests. However, based on mean scores, male participants $(n=13)$ had higher scores on most of the subtests (DH, NDH, Assembly) as compared to female participants $(n=17)$. These results suggest that male motorcyclists can perform neurophysiological activity under high noise exposure as compared to female. Ratio of male drivers road accidents higher as compared to female, which suggests that male motorcyclists are more prone to risk taking behaviour [39]. A field study by Ali et al., suggests that female participants showed higher cortisol (stress) level after on-field motorcycle ride (45 minutes) then male participants, and higher cortisol concentration reduces cognitive and neuropsychological activity [28][14];[41]. Study by Oliver et al., reported impairment in cognitive tasks (verbal memory, attention and spatial working memory) after acute psychosocial stress exposure. Spatial memory was reported to returned to baseline within 30 minutes, while verbal memory and attention impairment persists for up to 30 minutes, following stressor exposure [42]. Stress related cognitive impairments may persist for at least 30 minutes. Another study investigated the impact of elevated glucocorticoid levels on human perceptual learning, and results showed perceptual learning impairments from glucocorticoid [43]. Therefore, high noise exposure generates cortisol which could hinder neuropsychological-motor activities.

Gender differences among Con-G participants were also not significant $(p>0.05)$ for any Purdue Pegboard subtests. Overall, the results did not show any significant $(p>0.05)$ gender differences, however, based on mean scores, Con-G's female participants $(n=13)$ had higher scores on all of the subtests as compared to male participants $(n=17)$. These results provide the group norm of Malaysian adults (19 - 24 yrs.) which has not been investigated previously. However, emphasis should be placed by the policymakers to conduct cognitive and neurophysiological functioning assessment of motorcyclists before approval of driver's license and should be readministrated over scheduled time. While in case of minor or major road accidents, motorcyclist's cognitive and neurophysiological assessment should be enforced as a law.

The strength of the study was the diversified participants demography and larger sample size $(n=60)$. For future studies, individual parameters such as personality type, subjective noise measurement, socioeconomic levels, and annoyance should be included to draw a more comprehensive effects of noise on cognitive function.

TABLE 3

Gender differences among Experimental and Control Group participants 


\begin{tabular}{lcccc}
\hline $\begin{array}{l}\text { Purdue Pegboard } \\
\text { Subtests }\end{array}$ & Groups & Mean \pm SD & Mean \pm SD & P-value \\
\hline & & & \\
Dominant Hand & Experimental & Male $(n=13)$ & Female $(n=17)$ & \\
\cline { 2 - 3 } Non-Dominant Hand & & $13.7 \pm 1.1$ & $13.4 \pm 1.6$ & .599 \\
Both Hands & $13.2 \pm 1.2$ & $12.8 \pm 1.3$ & .415 \\
Assembly & $11.5 \pm .9$ & $11.7 \pm 1.4$ & -.173 \\
& & $30.6 \pm 4.3$ & $30.3 \pm 4.1$ & .325 \\
Dominant Hand & Control & Male $(n=17)$ & Female $(n=13)$ & \\
Non-Dominant Hand & & $14.9 \pm 1.2$ & $15.3 \pm 1.5$ & .354 \\
Both Hands & $13.5 \pm 1.3$ & $14.3 \pm 1.7$ & .185 \\
Assembly & $12.11 \pm 1.4$ & $12.9 \pm 1.1$ & .082 \\
\hline
\end{tabular}

\section{CONCLUSION}

It can be concluded that motorcycle noise does act as a source of stressor which could affect neurophysiology performance. Results showed distinctive difference between the motor activity performance between the motorcyclists' participants who operated under control laboratory exposure $(65 \mathrm{dBA})$ and artificially induced motorcycle noise exposure (>90 dBA). This study validates the negative influence of noise on neurophysiological (dexterity - motor activity) function. It also addresses the need of investigation on more mental health of high motorcycle noise exposure by using standardized protocols and provide solutions to that.

\section{ACKNOWLEDGMENT}

The authors are grateful to all the participants who participated and a very special thanks to Dr Subramaniam Karuppannan for his consistent guidance and support to complete this project. A very great appreciation to Universiti Teknologi MARA, Faculty of Health Sciences, and department of Occupational Health for providing all the facilities that were required.

\section{REFERENCES}

[1] L. Y. Le Loo, J. Corcoran, D. Mateo-Babiano, and R. Zahnow, "Transport mode choice in South East Asia: Investigating the relationship between transport users' perception and travel behaviour in Johor Bahru, Malaysia," J. Transp. Geogr., vol. 46, pp. 99-111, 2015, doi: 10.1016/j.jtrangeo.2015.06.011.

[2] T. P. Hsu, Ahmad Farhan Mohd Sadullah, and N. X. Dao., "A comparative study on motorcycle traffic development of Taiwan, Malaysia and Vietnam," J. East. Asia Soc. Transp. Stud., vol. 5, no. 10, pp. 179-193, 2003.

[3] A. Ahmed, A. F. M. Sadullah, and A. S. Yahya, "Errors in accident data, its types, causes and methods of rectificationanalysis of the literature," Accid. Anal. Prev., no. 8, pp. 0-1, 2017, doi: 10.1016/j.aap.2017.07.018.

[4] WHO, "Global status report on road safety 2013 'supporting a decade of action, Luxembourg," Luxembourg, 2013.

[5] H. Hussain, R. Umar, R. Sohadi, a Farhan, and M. Dadang, "Key components of a motorcycle traffic system: A study aong the Motorcycle Path in Malaysia," IATSS Res., vol. 29, no. 1, pp. 50-56, 2005, doi: 10.1016/S0386-
1112(14)60118-7.

[6] H. Rashid et al., "Motorcyclist muscle fatigue index: An effort to help reducing motorcycle accidents," Contemp. Ergon. Hum. Factors 2014 Proc. Int. Conf. Ergon. Hum. Factors 2014, Southampton, UK, 7-10 April 2014, p. 425. CRC Press, vol. 2, 2014.

[7] M. M. Abdul Manan and A. Várhelyi, "Motorcyclists' road safety related behavior at access points on primary roads in Malaysia - A case study," Saf. Sci., vol. 77, pp. 80-94, 2015, doi: 10.1016/j.ssci.2015.03.012.

[8] N. H. N. Rahman, K. A. Baharuddin, and S. M. S. Mohamad, "Burden of motorcycle-related injury in Malaysia," Int. J. Emerg. Med., vol. 8, no. 1, pp. 4-9, 2015, doi: 10.1186/s12245-015-0065-4.

[9] K. Malone, A. Silla, C. Johanssen, and D. Bell, "Safety, mobility and comfort assessment methodologies of intelligent transport systems for vulnerable road users," Eur. Transp. Res. Rev., vol. 9, no. 2, 2017, doi: 10.1007/s12544-017-0235-y.

[10] L. C. den Boer and A. Schroten, "Traffic noise reduction in Europe," 2007. doi: 07.4451.27.

[11] Royal Malaysia Police, "Royal Malaysia Police Annual Report, 2009," Kuala Lumpur, 2009.

[12] A. Ali et al., "Epidemiological root cause analysis of noise and physio - psycho impacts related to motorcycle road accidents," J. Sci. Res. Dev., vol. 3, no. 5, pp. 150-156, 2016, [Online]. Available: http://jsrad.org/wp-content/2016/Issue 5, 2016/23j.pdf.

[13] S. J. Lupien et al., "Cortisol levels during human aging predict hippocampal atrophy and memory deficits.," Nat. Neurosci., vol. 1, pp. 69-73, 1998, doi: 10.1038/271.

[14] S. J. Lupien et al., "Stress hormones and human memory function across the lifespan," Psychoneuroendocrinology, vol. 30, pp. 225-242, 2005, doi: 10.1016/j.psyneuen.2004.08.003.

[15] J. Padmanaban and V. Eyges, "Characteristics of Motorcycle Crashes in the U.S," Proc. 4th Int. Road Traffic Accid. Database Conf. Road Saf. Data Collect. Anal. Target Setting Monit. Performances Progress, Seoul, South Korea, 2009.

[16] M. G. Masuri, K. A. M. Isa, and M. P. M. Tahir, "Children, Youth and Road Environment: Road Traffic Accident," Procedia - Soc. Behav. Sci., vol. 38, no. 1, pp. 213-218, 2012, doi: 10.1016/j.sbspro.2012.03.342.

[17] H. D. Harvey, J. O. Hetherington, A. Woodside, and C. Jordan, "Noise induced hearing loss in motorcyclists," Assoc. Eur. Transp., 2002.

[18] J. Peraphan, K. Hermann, and M. Markus, "The conundrum of the motorcycle in the mix of sustainable urban transport," Transp. Res. Procedia, vol. 25, pp. 4873-4894, 2017, doi: 10.1016/j.trpro.2017.05.365.

[19] A. W. McCombe, "Hearing loss in motorcyclists: occupational and medicolegal aspects," J. R. Soc. Med., vol. 96, no. 1, pp. 7-9, Jan. 2003, doi: 10.1258/jrsm.96.1.7.

[20] ISVR Consulting University of Southampton, "Noise levels under motorcycle helmets," 2014. http://www.isvr.co.uk/at_work/m_cycle.htm (accessed Feb. 17, 2015).

[21] M. Basner et al., "Auditory and non-auditory eff ects of 
noise on health," Lancet, vol. 6736, no. 13, pp. 1-8, 2014, doi: 10.1016/S0140-6736(13)61613-X.

[22] S. L. You, "A study on the capacity and LOS under mixed traffic," National Taiwan University, 1993.

[23] N. Abdoli et al., "Poor mental health status and aggression are associated with poor driving behavior among male traffic offenders," Neuropsychiatr. Dis. Treat., vol. 11, pp. 20712078, 2015.

[24] J. Kennedy, M. Carley, I. Walker, and N. Holt, “On-road and wind-tunnel measurement of motorcycle helmet noise," J. Acoust. Soc. Am., vol. 134, no. 3, p. pp 2004-2010, 2013, doi: 10.1121/1.4817913.

[25] A. Ali, N. C. Dom, R. M. Hussain, S. Karuppannan, and M. Abdullah, "Auditory Profile of Undergraduate University Motorcyclists: Prevalence of Hearing Loss and Hearing Impairment," EnvironmentAsia, vol. 11, no. 1, pp. 217-229, 2018, doi: 10.14456/ea.2018.16.

[26] A. Ali, R. M. Hussain, M. Abdullah, and N. C. Dom, "AtEar Noise Levels Under the Helmet: A Field Study on Noise Exposure of Young Motorcyclists," J. Fundam. Apllied Sci., vol. 10, no. 3S, pp. 218-231, 2018.

[27] B. C. Ross, "Noise exposure of motorcyclists," Occup. Hyg., vol. 33, pp. 123-27, 1989.

[28] A. Ali and R. M. Hussain, "Cognitive Impairment among Young Motorcyclists: A controlled study," Environ. Proc. J., pp. 1-9, 2018.

[29] M. Picard, S. a. Girard, M. Simard, R. Larocque, T. Leroux, and F. Turcotte, "Association of work-related accidents with noise exposure in the workplace and noise-induced hearing loss based on the experience of some 240,000 personyears of observation," Accid. Anal. Prev., vol. 40, pp. 16441652, 2008, doi: 10.1016/j.aap.2008.05.013.

[30] M. G. Masuri, A. Dahlan, A. Danis, and K. A. Isa, "Attitude towards Safe Driving Scale (ASDS-46) as a Future Predictor in Determining a Young Adult Quality Of Life : Part II," Environ. Proc. J., vol. 2, no. 5, p. 363, 2017, doi: 10.21834/e-bpj. v2i5.705.

[31] D. Norfazila, A. Mustaffa, and M. Ghazali, "Speeding Intention among Young Urban Drivers," Asian J. Behav. Stud. AjBeS, vol. 2, no. 7, pp. 43-51, 2017.

[32] K. P. Waye, J. Bengtsson, R. Rylander, F. Hucklebridge, P. Evans, and A. Clow, "Low frequency noise enhances cortisol among noise sensitive subjects during work performance," Life Sci., vol. 70, pp. 745-758, 2002, doi: 10.1016/S00243205(01)01450-3.

[33] A. Liebl and H. Jahncke, "Review of research on the effects of noise on cognitive performance 2014-2017," 2017.

[34] H. Jahncke, S. Hygge, N. Halin, A. Marie, and K. Dimberg, "Open-plan office noise: Cognitive performance and restoration,” J. Environ. Psychol., vol. 31, no. 4, pp. 373-382, 2011, doi: 10.1016/j.jenvp.2011.07.002.

[35] W. Warren, M., Pendleton, H.M. and Schultz-Krohn, "Evaluation and treatment of visual deficits following brain injury," Occup. Ther. Pract. Ski. Phys. Dysfunct., pp. 532-572, 2006.

[36] K. C. Parsons, "Environmental ergonomics: A review of principles, methods and models," Appl. Ergon., vol. 31, pp.
581-594, 2000.

[37] L. Tzivian et al., "Effects of long-term outdoor air pollution and noise on cognitive and psychological functions in adults,” Int. J. Hyg. Environ. Health, vol. 218, no. 1, pp. 1-11, 2015, doi: 10.1016/j.ijheh.2014.08.002.

[38] A. Etkin and T. D. Wager, "Reviews and Overviews Functional Neuroimaging of Anxiety: A Meta-Analysis of Emotional Processing in PTSD, Social Anxiety Disorder, and Specific Phobia," Am J Psychiatry, no. October, pp. 14761488, 2007.

[39] M. M. Abdul Manan and A. Várhelyi, "Motorcycle fatalities in Malaysia," IATSS Res., vol. 36, no. 1, pp. 30-39, 2012, doi: 10.1016/j.iatssr.2012.02.005.

[40] A. Ali, R. M. Hussain, N. C. Dom, and M. Abdullah, "Noise-Induced Cortisol Assessment among Young Motorcyclist : A field study," Asian J. Qual. Life, vol. 3, no. 13, pp. 117-127, 2018, doi: 10.21834/ajqol.v3i13.168.

[41] S. J. Lupien, B. S. McEwen, M. R. Gunnar, and C. Heim, "Effects of stress throughout the lifespan on the brain, behaviour and cognition," Nat. Rev. Neurosci., vol. 10, no. 6, pp. 434-445, 2009, doi: 10.1038/nrn2639.

[42] J. S. Olver, M. Pinney, P. Maruff, and T. R. Norman, "Impairments of Spatial Working Memory and Attention Following Acute Psychosocial Stress," Stress Heal., vol. 31, no. 2, pp. 115-123, 2013, doi: 10.1002/smi.2533.

[43] S. J. Lupien, C. W. Wilkinson, S. Brière, C. Ménard, N. M. K. Ng Ying Kin, and N. P. V Nair, "The modulatory effects of corticosteroids on cognition: Studies in young human populations," Psychoneuroendocrinology, vol. 27, pp. 401416, 2002, doi: 10.1016/S0306-4530(01)00061-0.

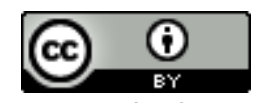

Journal of Applied and Emerging Sciences by BUITEMS is licensed under

a Creative Commons Attribution 4.0 International License. 